\title{
A Survey of English Learning Based on M-learning - Case Study of Students of Grade 2017, BIPT
}

\author{
Qingyue Luo \\ Beijing Institute of Petrol-chemical Technology, China \\ Wensheng Deng ${ }^{1}$ \\ Beijing Institute of Petrol-chemical Technology, China
}

\begin{abstract}
In the contemporary time, mobile devices are particularly popular among college students; so does it on Beijing Institute of Petrol-chemical Technology. And the paper aims to make clear of English learning involved the students of Grade 2017, BIPT, by using mobile equipment. It adopts survey study to the students in the project, which focuses on the detailed investigation, such as gender, program, application, time, length, place, material, style, major and effect, and etc. Based on the results of the data about the students' application of mobile devices into English learning, the survey is likely to give tips to the students and provide Dept. of Foreign Languages and other relevant departments of BIPT with some suggestion, which is of significance to improve English teaching and learning.
\end{abstract}

Index Terms - mobile devices, English learning, survey, pluralism

\section{INTRODUCTION}

The saying, "Good tools are prerequisite to the successful execution of a job," stresses that a good tool is vital to do anything well. So it does to English teaching and learning. At the present, which is called the Age of Internet, it is not too much of importance enough for us to stress the Age. In particular, young people cannot be separated with the Internet even for a single moment; and they are often labeled with a tag "Give me network, or give me death", 2 to some of contemporary college students, they often feel heart-broken when Wi-Fi, Wireless Fidelity, is disconnected suddenly. Such a case is not overstated at all. Thus, it is impossible for English teachers to change but adapt to the Age of Internet in their teaching job. For teachers, especially teachers of English, have to naturally make full use of the networks, the good tools to benefit both students and teachers. It is the Age of Internet that has forced English teaching and learning to advance forward. Moreover, in China the unique status of English is another factor, which have aroused teachers' and learners' awareness and attracted their attention to the course, that is to say, every college student, whatever he is majoring in, he is supposed to select English course. It is absolutely true that English in China is No.1 Course because of large volume of attendants; no other course could be competitive with the biggest number of the selected Course. Thus, the efficiency of English teaching and learning is involved into all levels of administrations at college. Moreover, the result of the course is something connected with a teacher's promotion and students' employment over China. That is one of the motivations of the survey of English learning as well.

English teaching in China, from its initial stage of dumb teaching, the first phase, then, recorder teaching the second phase, has leaped to online teaching the third one, and updated to mobile teaching the last one. Every update of English teaching is tied closely to new technology and new tool. In the current of mobile devices employed popularly among masses, teachers of English, who are ignorant of the new mobile Appliances, such as smart phones, will definitely be washed away, swept and swallowed by such kind of isolation or ignorance; worse, though it brings downside to the students. Unfortunately, no doubt, the mobile appliances are vital to master any language, let alone mention English learning, for which is easy to grasp than Chinese. However, the teachers of English at Beijing Institute of Petrol-chemical Technology (Hereafter initialed as BIPT) are not quite clear about the status of mobile-learning among their students. That is the content to be investigated throughout the survey so that the investigators could provide with some proposals to the relevant sections of BIPT for future improvement.

\section{A. Foreign Research}

Since the concept of mobile learning (shortened as m-learning) is first put forward in the United States in 2000, researches and practices on this aspect have been widely spread over the world. Stanford University of the USA is the

1.Wensheng Deng is the corresponding author of the paper. The survey is a URT (University Research Training) Project of BIPT (Beijing Institute of Petrol-chemical Technology); other team members are Yu Li, Simeng Li, Xin Tan and Jinting Zhang.

2. It is a parody of "Give me liberty, or give me death" by the author of the thesis. 
first university to adopt the mobile learning in foreign language learning over the world. In 2002, the learning lab of Stanford University has conducted an experiment to learn English words by using SMS, which means short messaging service. In 2004, a Bangladeshi American called Salman Khan (Liu \& Ge, 2004, p13-17) has employed Internet to teach his relatives math simply by chance. It is the occasional teaching by using Internet that Salman Khan has carved out a completely new space in teaching and learning over the world. In 2006, Salman Khan has established a college entitled Khan Academy, using mobile Internet to teach foreign languages and other courses in class. In 2005, BBC, British Broadcasting Corporation, began to use radio and text messages to teach English in West Africa. At the same time, Europe's m-learning program, mobile learning, also applies short messages to teach Finnish. In 2006, an Australian doctoral student set up his own WAP (Wireless Application Protocol) website in South Korea, by which 30 students have completed WAP-based tasks and communicated with classmates and teachers. Thus, from the retrospect of m-learning mentioned above, it is clear that the theory and practice abroad is popular.

\section{B. Domestic Research}

In China, Professor Gui Qingyang of Zhejiang International Studies University is kind of somebody remarkable in m-learning, for who has first connected mobile learning with foreign language learning and teaching. His thesis, entitled "M-learning: The Future of Foreign Language Learning in Chinese Context", has been published in the journal, Technology Enhanced Foreign Language Education, in 2003. Gui (2003, p14-17) advocates that "M-learning is a new revolution in learning, which is the future of foreign language learning in China". And Han Ling, Man Zhaohui and Shao Wen (2004, p43-45) have explored mobile English teaching and assessment of the teaching. Among other scholars of m-learning, Ma Junbo (2007, p30-36) is one of the representatives. He tries to apply m-learning to foreign language teaching, and alleges foreign language teaching aided by computer (CALL) to shift to m-learning (MALL) granted by classroom context, educational technology and linguistic development.

Now, it is clear for us to see the foreign researches have been concentrating upon teaching knowledge, especially in the USA; and the domestic researchers have paid more attention to teaching and learning. However, both of the two kinds are ignorant of gender, program, application, time, length, place, material, style, major and effect in m-learning. These are points of departure of the survey.

\section{Survey Of M-Learning Of English About The Students Of Grade 2017, BIPT}

The goal of the survey is to get a clear idea of m-learning of English involved the students of Grade 2017, BIPT. However, the focus of the research is not the relativity to English competence and performance, nor is the comparison of English levels among the respondents, by m-learning. We intend to figure out how many students of Grade 2017 are using mobile devices in learning English, what kinds of English resources they prefer, and what time is available to them. It is our hope that we get some objective findings from the data. And, based on the survey, some tips will be given to the students, and proposals to the Dept. of Foreign Languages and other relevant departments of the college, to enhance English teaching, learning and administration.

Throughout the research, the method of document and material, surveying method, and questionnaire method are combined together. The questionnaires, both digital and paper ones, are supposed to be filled in online and offline by interviewees. Some foreign and domestic file and thesis are adopted. The students of Grade 2017 are respondents of the survey. And some interviews or conversations will be held to collect response from the respondents to verify the data of the survey. There are 1,700 student enrollments of Grade 2017 in BIPT, i.e. the population of the survey. And 250 respondents from each department are picked at random to be as samples to fill in the online questionnaire; the percentages of male and female of the respondents are identified with 1to1, but in practice the ratio is 13 to12, male is a little higher than female; other100 respondents are picked to interview by E-mail, the ratio of male and female is 11 to 9; and another 50 are picked to be interviewed by telephone, the sex ratio is 1 to 1 ; and other 100 are picked to write the paper questionnaire, the percentage is 3 to 2 . All the samples of 500 respondents are not repetitive, which have accounted for $29.4 \%$ of the students, Grade 2017. Therefore, the data of the survey are reliable and accurate. And 3 repeated samples are eliminated and excluded by the researchers of the project, for which are not available enough to interfere with the findings and validity of the investigation, they can be negligible. In brief, descriptive way is adopted in the survey.

As to multiple channels, i.e., questionnaire online and offline (digital and paper questionnaire), interview, telephone and e-mail, adopted in the survey, it is the investigators' hope that they could get more reliable and objective data by using various methods, i.e., a kind of triangle proofs, to demonstrate some possible regularities, so that they can kick out rash or ridiculous questionnaire, in case some of the students are irresponsible to the survey. The interview is a sort of structured interview, in which topics and contents are designed in advance (Liu Runqing, 2005, p80).

Throughout the survey, the investigators are non-participant of the subjects enrolled, but are students of Grade 2017 as well. All instructors, who help the investigators, are from the departments which the subjects belong to, for it is convenient for them to find the respondents.

The survey lasts from November, 2017 till October, 2018. And the respondents are required to report their English learning with m-learning devices within one year after class. We are going to neglect the subjects' intelligence, prior knowledge of English. And the questionnaire are designed and written in Chinese so the subjects can understand it at 
one look.

\section{FINDINGS Of ThE SURVEY}

\section{A. Findings of Online Survey}

With the help from assistant instructors of the Departments or schools of BIPT, the team group of the survey is able to distribute 250 pieces of questionnaires to the respondents, the students of Grade 2017; there are 242 effective answer sheets, with 8 answer sheets deleted for failing to meet the demands of the survey, only accounting for $3.2 \%$ of the total, so the survey online is reliable and accurate. Among the 242 respondents, male percentage is 52.07\%, female 47.93\%; $25.21 \%$ are from A-level Class, $74.79 \%$ from B-level Class. ${ }^{3}$ There are $27.69 \%$ of the interviewees who own a desktop computer, $68.18 \%$ with a portable computer, $19.42 \%$ with an ipad, $80.99 \%$ with a smart phone, $14.05 \%$ with an MP3 or MP4 player, and $13.22 \%$ with an electronic dictionary.

The figures mentioned above are listed in the following histogram.

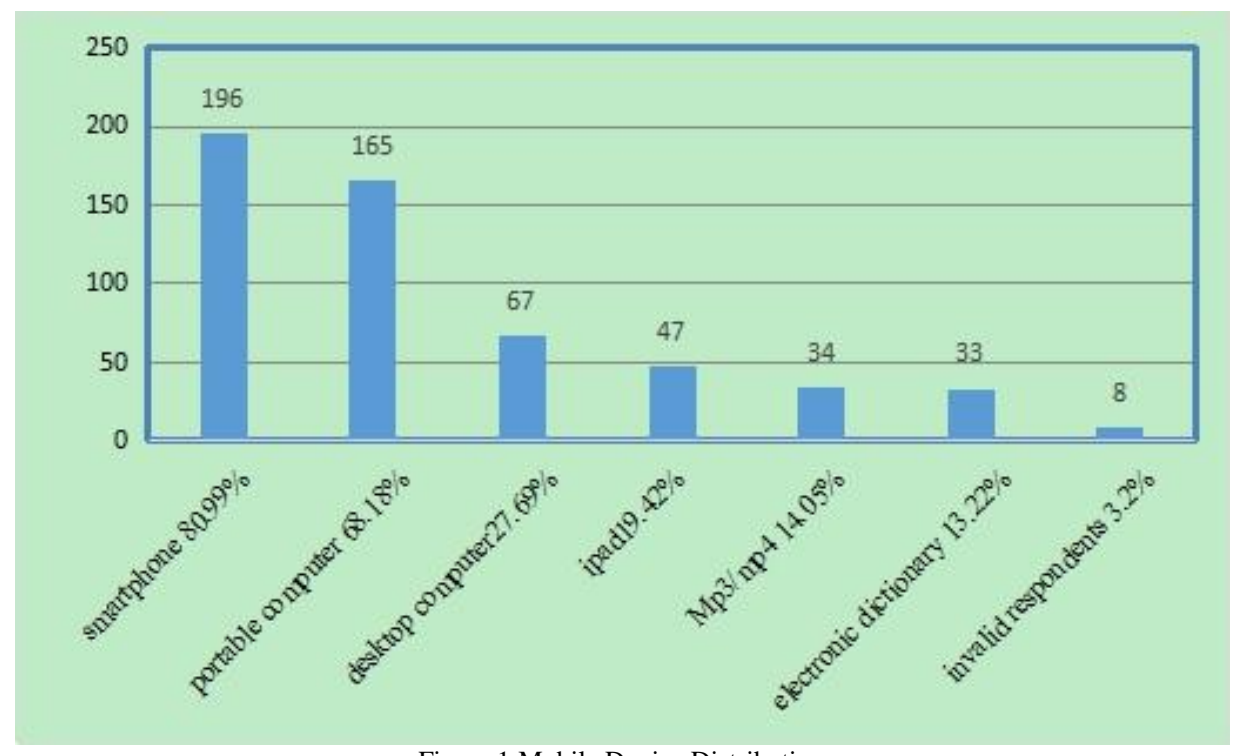

Figure 1 Mobile Device Distribution

When the respondents are asked whether he or she knows the concept of m-learning, 35.95\% of them say they have never heard of it before; $59.92 \%$ knows a little of it; and $4.13 \%$ say they are familiar with it. The percentages are indicated as below.

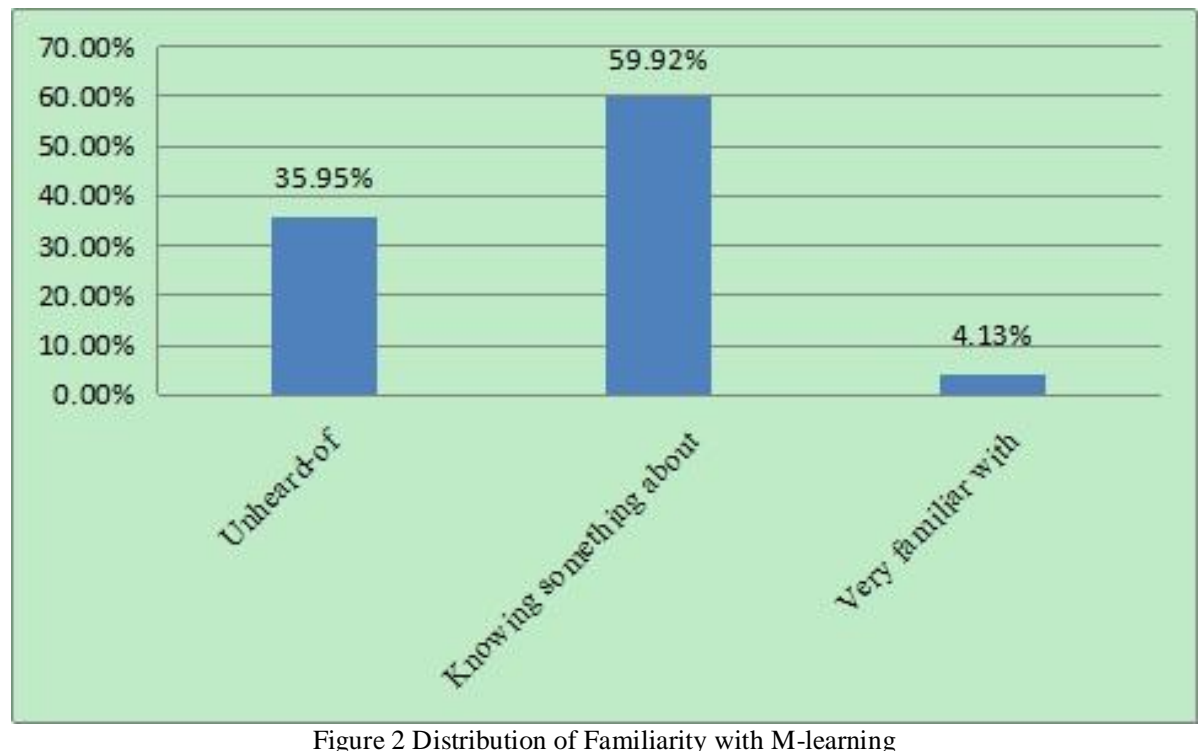

There are $21.9 \%$ of the respondents with frequent use of mobile Internet to learn English; $67.77 \%$ of them say they

3.There are two kinds of classes in BIPT, who are divided into A-level Class or B-level Class according to their marks in the first entrance exam of English. A-level Class is a little over 60 points if the full marks are 100; and others are B-level. 
occasionally make use of mobile Internet to do so; and $10.33 \%$ of them say they never use the mobile networks to learn English.

And when the subjects of the investigation adopt the mobile networks to learn English, $83.88 \%$ of them are preferable to employ through mobile App; $12.4 \%$ have the inclination to take a computer notebook; $3.72 \%$ are used to applying an MP3 or MP4 player. Here is a pie chart for the statistics.

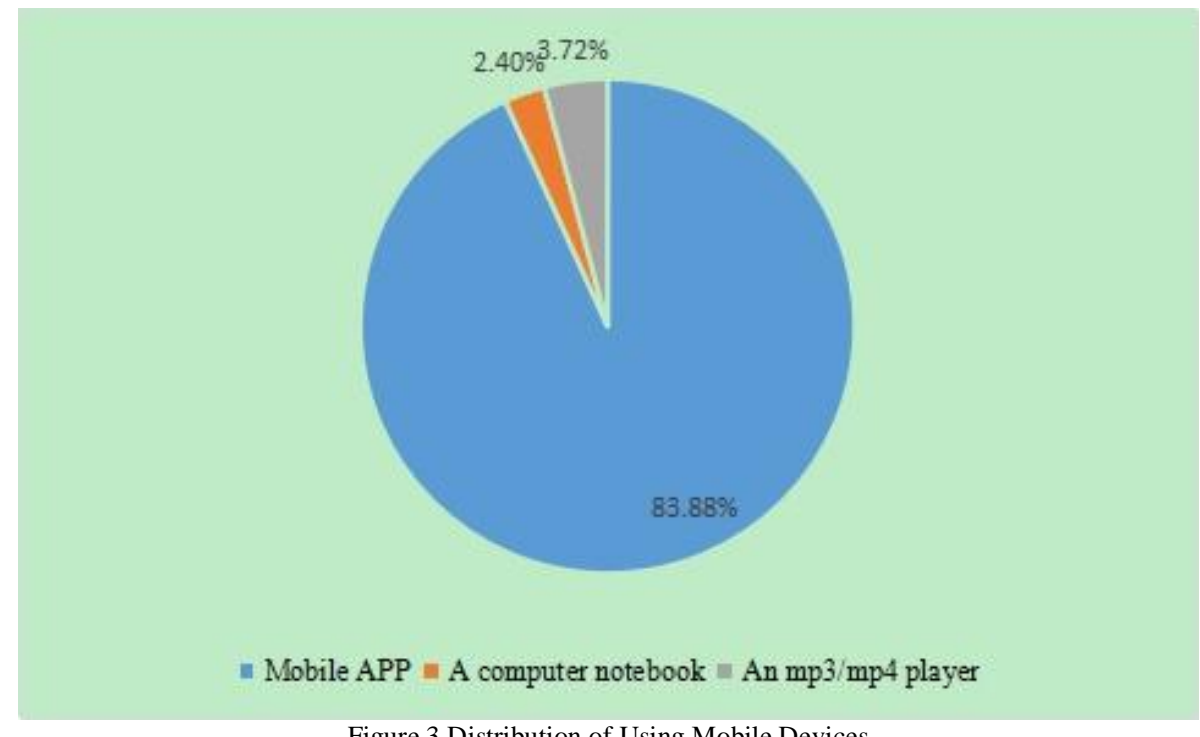

Figure 3 Distribution of Using Mobile Devices

There are $90.08 \%$ of the respondents to look up new words through mobile App in English learning; $38.84 \%$ of them listen to listening materials; $19.83 \%$ browse the Web; and another $8.26 \%$ of them chat online with native English to enhance their English level. The subsequent figures are listed here.

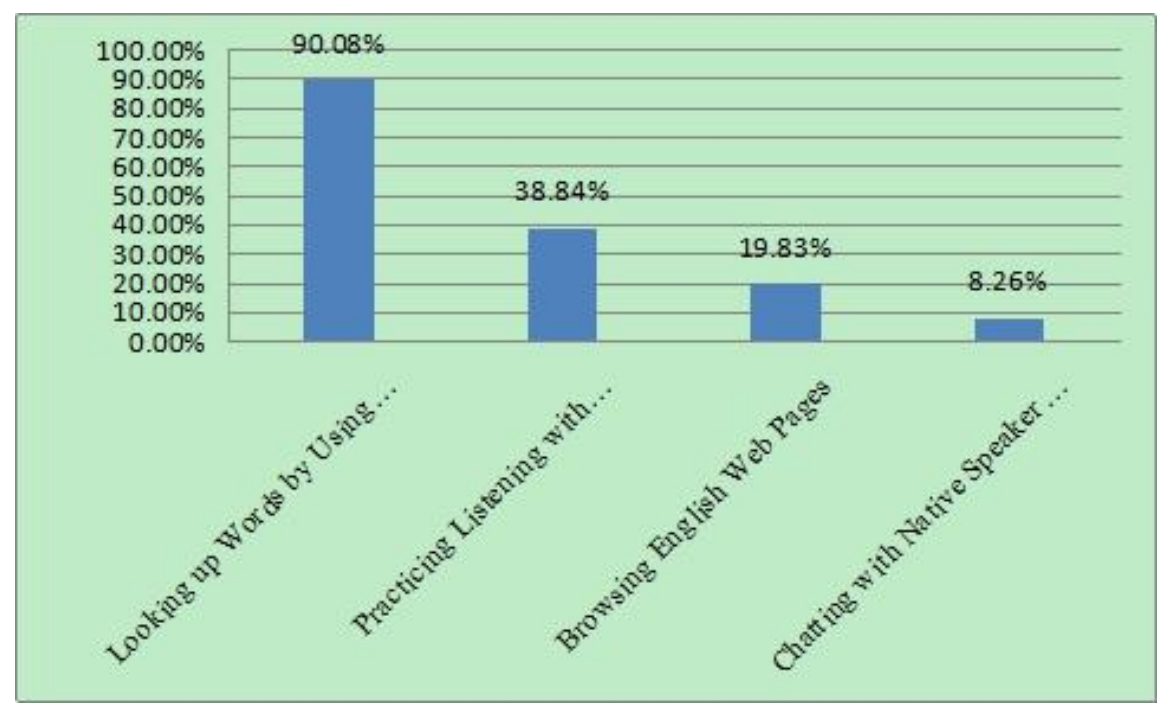

As to English learning with mobile App, $60.74 \%$ of the respondents do with the App or something the like. $56.2 \%$ of them make use of it to learn words by heart; $35.12 \%$ of them finish assigned translation, both from English to Chinese or vice versa, with the aid of the App; $24.38 \%$ use it to practice listening comprehension, $19.83 \%$ to dialogue with it in English, 16.53\% choose the App for writing English essays. And 33.47\% of them never apply the mobile App to English learning at all. 


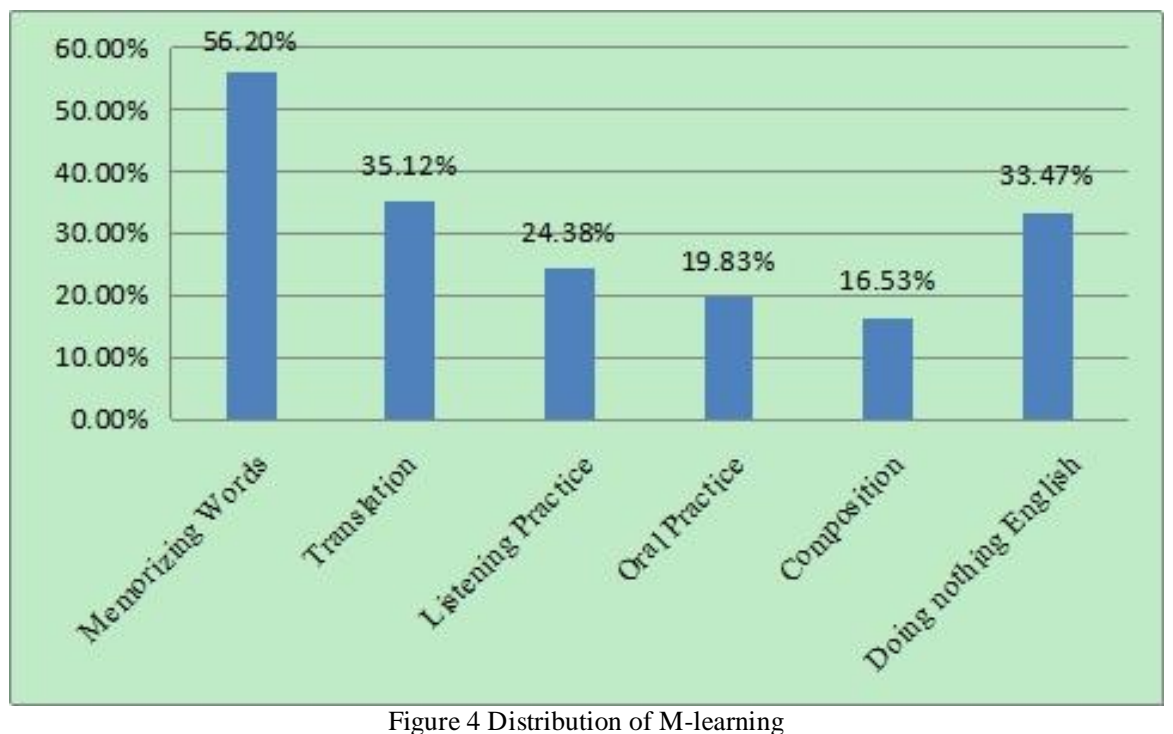

Among 39.26\% of the respondents, who have never applied the mobile App, 32.23of them are distracted by other information from the Internet, and they are not able to devoted to English studies, $25.62 \%$ because they are not getting used to English learning with a mobile phone; $25.62 \%$ of them have not done it because of the App without proper specifications and assessments; and $11.98 \%$ for the network speed and reliability are not quick enough or stable to use the mobile App.

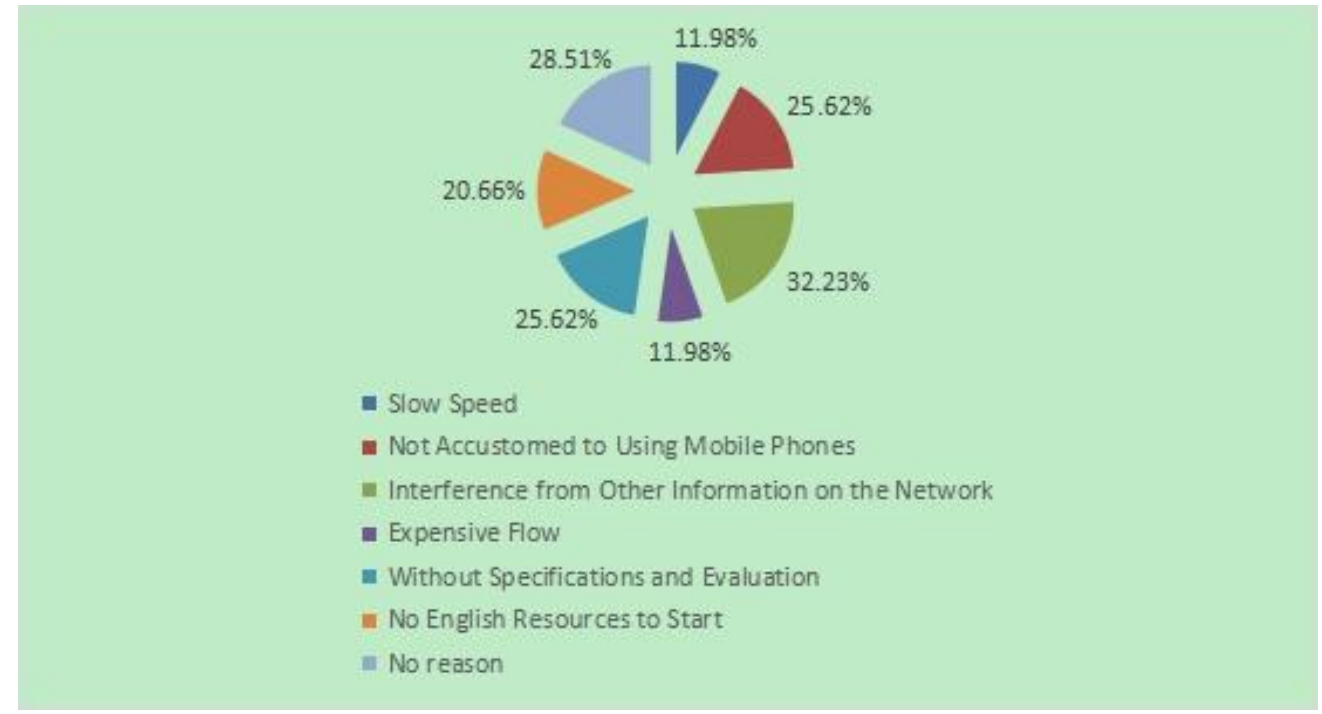

Figure 5 Distribution of not Using Mobile Devices

When it comes to the validity of English learning by using mobile devices, $54.13 \%$ of the respondents admit that it is effective for learning English; 35.95\% think its validity is just so-so, not ideal; $9.92 \%$ express the mobile Internet is of no help at all to learn or improve English. $48.35 \%$ of the students are most likely to use the mobile appliances when they have difficulty in finishing English assignments; $42.56 \%$ of them use the mobile before they go to bed; $28.93 \%$ prefer to do after class; it is more possible for $23.97 \%$ of the respondents to adopt it to learn English while they are waiting for vehicle. Besides the reason, 10.74 of the students would like to listen to lectures delivered by a distinguished professor for they are too far from the lectures' site to attend. 


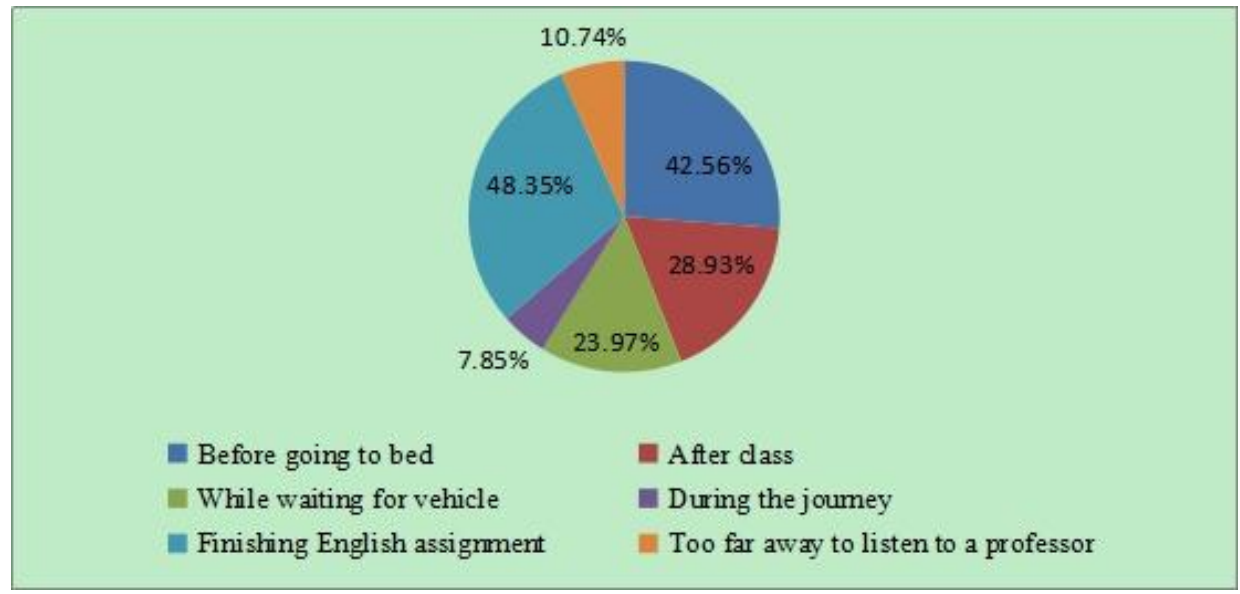

Figure 6 Distribution of Specific Period of Time of English by Using Mobile Devices

The time duration to learn English by using mobile devices are varied greatly. 47.93of the respondents says that they spend less than 30 minutes every day; $24.38 \%$ with between half an hour and an hour, $4.96 \%$ with over one hour, and $22.73 \%$ of them have barely touched the devices to learn English.

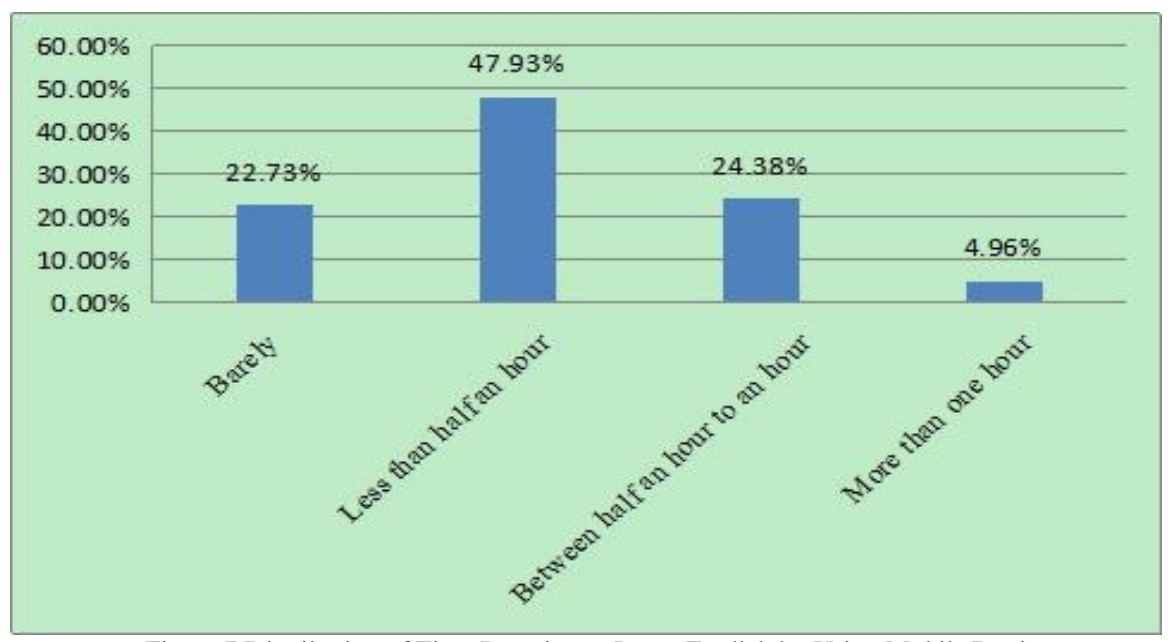

Figure 7 Distribution of Time Duration to Learn English by Using Mobile Devices

As to the purpose to learn English by using mobile devices, the respondents are different. $61.16 \%$ of them learn it with mobile equipment to strengthen basic skills of English, $71.94 \%$ to pass various levels of tests; $16.94 \%$ to understand more Anglo-American culture; $19.01 \%$ to prepare for future professionals.

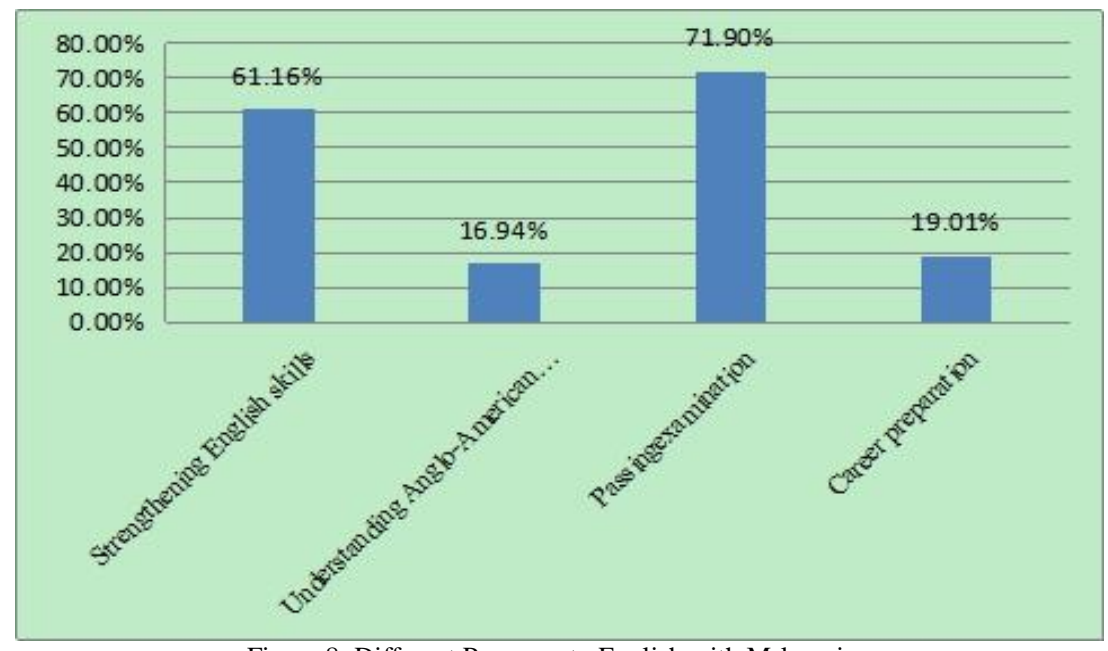

Figure 8: Different Purposes to English with M-learning

\section{B. Findings of Paper Questionnaires}

The Project has distributed 100 pieces of questionnaires, and 74 questionnaires are recovered. Among the completed 
surveys, $13.5 \%$ of them are from College of Chemical Engineering of BIPT, with sex ratio of 4 to $1 ; 13.5 \%$ from Material College with 7 to 3, 13.5\% from Information Technology and Engineering College with 4 to1, 59.5\% from Mechanical College with 29 to 15; among the Mechanical College, 36.4\% of the subjects are from specialty of the Process Equipment \& Control Engineering, 22.7\% from specialty of Oil Storage, 22.7\% from specialty of Electron-mechanical Engineering, 18.25 from specialty of Energy and Power Engineering.

Among the 74 questionnaires, $67.6 \%$ of them admit that they know something about m-learning, $13.5 \%$ express that they are quite familiar with it, and $13.5 \%$ say they have never heard of it before. $21.6 \%$ of the subjects say they are interested in English, 35.1\% are not in it; and $43.3 \%$ of the respondents are not good at English, with average level in English exam. In English learning, $18.9 \%$ frequently make use of the Internet, $67.6 \%$ occasionally with the use of mobile networks, $13.5 \%$ never with the use of it. $31.1 \%$ of the respondents use the mobile App to look up new words, $6.8 \%$ to improve listening comprehension by it; $36.5 \%$ of them say they use the App for both, and $25.6 \%$ use other various ways.

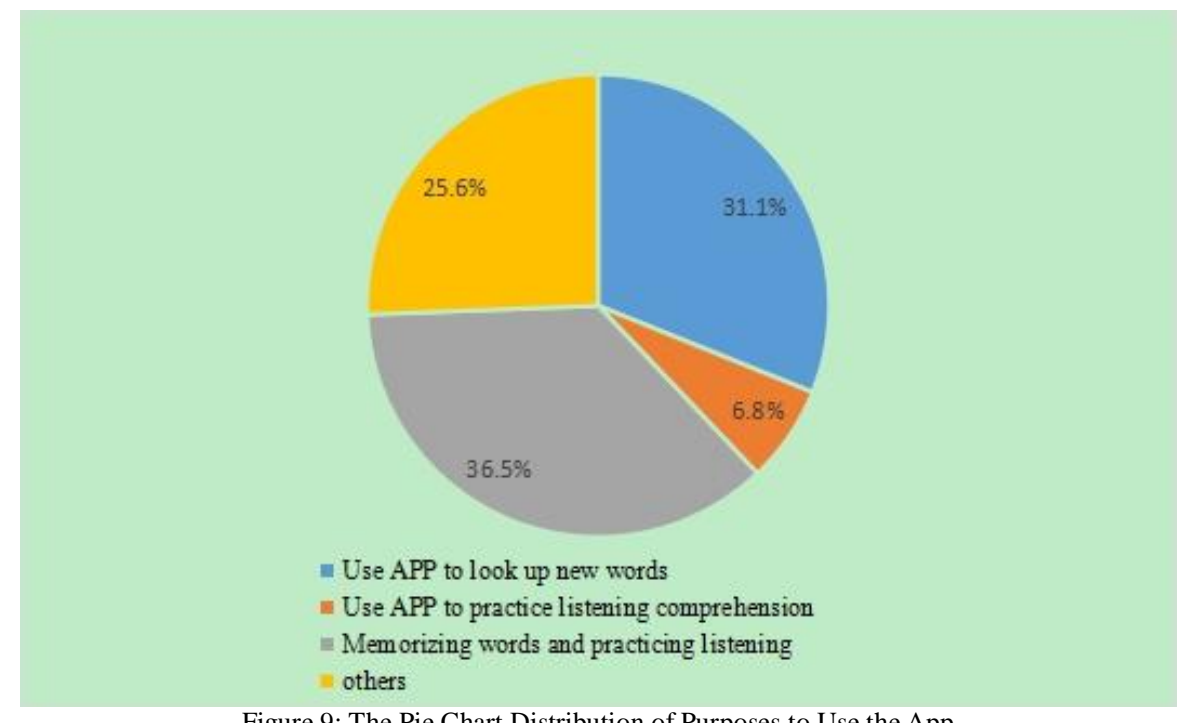

Figure 9: The Pie Chart Distribution of Purposes to Use the App

As to the types of the App, the findings are varied. 10.8\% use Memory App, 6.8\% with Auxiliary App, 36.5\% adopt multifunctional App; $45.9 \%$ have not used the App. The reasons not to use any learning software for them are different from person to person. 30.3\% are disturbed by other Web information to concentrate on English, 39.4\% have varied reasons, $30.3 \%$ of them with sole reason. $29.7 \%$ of the students say they use the App to deal with difficulties in assignments; $20.3 \%$ use it before they go to bed; $25.7 \%$ when they get bored, $8.1 \%$ in waiting for a vehicle, $16.2 \%$ at other occasions. And $14.9 \%$ spend more than an hour, $17.6 \%$ between half an hour and one hour, $39.2 \%$ within half an hour, $28.3 \%$ nothing.

TABLE I.

TIME DURATION TO LEARN ENGLISH

\begin{tabular}{|l|l|l|l|}
\hline Over 1 hour & Between half an hour and one & Within half an hour & Zero \\
\hline $14.9 \%$ & $17.6 \%$ & $39.2 \%$ & $28.3 \%$ \\
\hline
\end{tabular}

\section{Finding of E-Mail Survey}

The survey group has sent 100 samples, the ratio of male to female 11 to 9; and the ratio from Level A and B is 3 to 7 . Among them, 40\% say they frequently learn English, 30\% sometimes (so-so), 30\% not frequent; $39 \%$ of the respondents are interested with English, 24\% so-so, 37\% not at all. 20\% of them prefer to use Audio types, 50\% video ones, $30 \%$ pictures. $80 \%$ of the interviewees think m-learning is effective, $20 \%$ with no use at all.

TABLE II.

FREQUENCY TO LEARN ENGLISH

\begin{tabular}{|l|l|l|}
\hline \multicolumn{2}{|c|}{ FREQUENCY TO LEARN ENGLISH } \\
\hline $40 \%$ & sometimes (so-so) & infrequent \\
\hline & $30 \%$ & $30 \%$ \\
\hline
\end{tabular}

\section{Findings of Telephone Survey}

The survey has 50 respondents. The ratio of male to female is 1 to 1 , the ratio of Level A to B is 2 to $5.20 \%$ of them are interested in English, 24\% not strong, 56\% not interested in it. 40\% know something about m-learning or micro-learning, $22 \%$ not much, $38 \%$ nothing. $37.5 \%$ say the video is of most help; $25 \%$ are inclined to use audio, $37.5 \%$ with both, $12.5 \%$ for pictures. $40 \%$ of them have equipped with learning software, $60 \%$ not; $30 \%$ like to download materials to learn English, $20 \%$ by WeChat, QQ or other software. 


\section{CONCLUSIONS}

Obviously, the survey has both theoretical and realistic significance. On one hand, theoretically we get a basic map of English learning with mobile devices about Grade 2017 of BIPT. That is, from the online survey, we see there are $21.9 \%$ of the respondents with frequent use of mobile Internet to learn English; from the paper questionnaires, $18.9 \%$ of the subjects frequently make use of the Internet, $67.6 \%$ of them occasionally use mobile networks; and from the e-mail investigation, $40 \%$ of them say they frequently, $30 \%$ sometimes (so-so) use mobile devices to learn English. The data indicates that m-learning of English is acceptable or popular to some students.

On the other hand, realistically, from the data listed above, some proposals could be drawn to give the Dept. of Foreign Languages, or other administrations related with teaching affairs. $80.99 \%$ of Grade 2017 have a smart phone at least, so it is advisable for the teachers of English at BIPT to make good use of them in class as a teaching aid; $68.18 \%$ have portable PC, $27.69 \%$ with desktop PC, $19.42 \%$ with an iPad, and English teachers could regularly assign some quiz or share some websites to learn English with their students, for at least they have no worry about the mobile devices at all. And most of the respondents have not adopted radio broadcasting, MP3/MP4 and electronic dictionaries, they are not suitable in learning English in BIPT. Thus, we hope that the English radio broadcasting station be stopped using any more.

And, $83.88 \%$ of the students have been tending to use mobile App, and $90.08 \%$ of them often look up new words by using the Apps, so the English teachers are supposed to learn online technology to check the students' vocabularies by the App, or establish a series of rules and regulations to motivate them. As to the teachers of English at BIPT, they had better learn to make use of the widely adopted Apps, ${ }^{4}{ }^{2}$ which are designed for English learning, so that they can have interactions with the students in or after class. And all levels of the administrations, like teaching section, network labs and language labs should be provided with online classroom and equipment, have the Apps installed, updated in time, and make sure they are smooth in use. To English Department, authorities of BIPT, a detailed teaching plan and program should be designed for the whole body of the students, not only Grade 2017, but also students of other grades, and prepare online resources for the teachers; the Institute should be responsible for the funds and projects to encourage the teachers, who could be pioneers in the field of m-learning.

Third, $48.35 \%$ of the students use mobile networks to learn English in finishing their assignments, $42.35 \%$ would like to use m-learning before going to bed; and $28.93 \%$ apply them into learning after class, so the three choices of the time to publish materials online are most effective.

For the students of Grade 2017, the subsequent tips are of importance to learn English with efficiency. Those $32.23 \%$ of the students, who are distracted by other online information, should have a plan to design and decide for their future career, or have other classmates to remind or supervise him at any time; $11.98 \%$ of them, who find slow speed of the Internet, are better to learn in the classroom of BIPT for a quicker flow of the Internet; $25.62 \%$, who have no guidance or evaluation in learning English, can go to their English teacher for help or find a suitable App with such a system instead.

\section{Limitations Of THE SURVEY}

The reporter of the survey has some limitations as well. First, the investigators of the project have not given sufficient evidence to every finding, just analysis and synthesis with some figures. Second, the survey is merely a reporter of Grade 2017 at BIPT, an illustration of m-learning of English, but it has nothing to do with the respondents' mentality and psychology, which is a key factor to affect upon English performance. Third, the respondents of the survey are not inclusive from the whole body of Grade 2017, and the variables of the survey are far from absolutely reliable.

\section{REFERENCES}

[1] Gui, Qingyang. (2003). M-learning: The Future of Foreign Language Learning in Chinese Context, Technology Enhanced Foreign Language Education, 2, 14-17.

[2] Han, Ling., Man, Zhaohui. \& Shao, Wen. (2004). Mobile English Language Teaching: Components, Characteristics and Evaluation, Distance Education in China, 23, 43-45.

[3] Liu, Runqing. (eds.) (2005). Research Methods in Foreign Language Teaching. Beijing: Foreign Language Teaching and Research Press, 80.

[4] Liu, Yujun. \& Ge, Shufang. (2004).Literary Survey of M-learning Abroad, Modern Technology of Education, 3, 13-17.

[5] Ma, Junbo. (2007). Interfacing M-learning with Foreign Language Learning: From CALL to MALL, Technology Enhanced Foreign Language Education, 117, 30-36.

4. For the students' convenience, the URT Project recommends the following as well to those who are not able to find any m-learning App or websites related to English. For spoken English practice, MyET, and Fluency English are good Apps, and website http://dwz.xdfan.cn; for English writing, www. Pigai.org; for word memorizing App, Bubeidanci(不背单词), Leici(乐词), Baicizhan (百词斩), and http://www.shanbay.com. The authors of the paper find them online, through Baidu search engine, https://www.baidu.com, 3/5, 2019. 
Qingyue Luo was born in Yutai County of Shandong Province of China in 2000. She is a sophomore majoring in Environmental Engineering at Beijing Institute of Petrol-chemical Technology. She is interested in English and Chinese Traditional Culture. Besides, she is committed to contributing to the improvement of China's environment.

Wensheng Deng was born in Anhua County, Hunan Province of China in 1967. He received his M.A.in literature from Central South University of China in 2002, and was further trained his academics at Harding University of the USA from 2007 until 2008.

And now he is Associate Professor of Anglo-American Literature of the Dept. of Foreign Languages at Beijing Institute of Petrol-chemical Technology, China. His scholastic studies cover Comparative Literature, Translation Studies, Film Studies and Politics.

Mr. Deng is a member of Chinese Association of Foreign Language Teachers. And he has published more than 30 papers home and abroad. 